\title{
The Cardiovascular Benefits Associated with the Use of Sodium-glucose Cotransporter 2 Inhibitors - Real-world Data
}

\author{
Baptist Gallwitz \\ Medizinische Klinik IV, University of Tübingen, Tübingen, Germany
}

$\mathrm{T}$ ype 2 diabetes (T2D) is associated with numerous comorbidities that significantly reduce quality of life, increase mortality and complicate treatment decisions. In a recent cardiovascular outcomes trial, Empagliflozin Cardiovascular Outcome Event Trial in Type 2 Diabetes Mellitus Patients (EMPA-REG OUTCOME), the sodium-glucose cotransporter 2 (SGLT2) inhibitor empagliflozin was shown to reduce cardiovascular (CV) mortality and heart failure in high-risk patients with T2D with a previous CV event or with established CV disease (CVD). Recently published data from the Canagliflozin Cardiovascular Assessment Study (CANVAS-PROGRAM) study suggested that the cardiovascular benefits of empagliflozin are also seen with the SGLT2-inhibitor canagliflozin, indicating a class effect of SGLT2 inhibitors. Evidence for a class effect has also been shown by meta-analyses and real-world studies, including the Comparative Effectiveness of Cardiovascular Outcomes in New Users of SGLT-2 Inhibitors (CVD-REAL) and The Health Improvement Network (THIN) databases. These findings also suggest the results of EMPA-REG OUTCOME can be applied to patients with T2D with a broader CV risk profile, including people at low risk of CVD.

\section{Keywords}

Cardiovascular outcome trials, dapagliflozin, empagliflozin, canagliflozin, real-world data, sodium-glucose cotransporter 2, type 2 diabetes

Disclosures: Baptist Gallwitz discloses the following: Board Member/Advisory Panel for Amgen, AstraZeneca, Boehringer Ingelheim, Eli Lilly \& Co., Janssen, Merck Sharp \& Dohme, Mylan, Novartis, Novo Nordisk. Speaker honoraria: Amgen, Abbott, AstraZeneca, Bristol Myers Squibb, Boehringer Ingelheim, Eli Lilly \& Co., Merck Sharp \& Dohme, Novo Nordisk, Sanofi.

Acknowledgements: Medical writing assistance was provided by Katrina Mountfort, Touch Medical Media and supported by AstraZeneca. Baptist Gallwitz would like to thank Anna Norhammer for her help and input to this article.

Compliance with Ethics: This study involves a review of the literature and did not involve any studies with human or animal subjects performed by any of the authors.

open Access Statement: This article is published under the Creative Commons Attribution Noncommercial License, which permits any non-commercial use, distribution, adaptation and reproduction provided the original author(s) and source are given appropriate credit. () The Author 2018.

Authorship: All named authors meet the criteria of the International Committee of Medical Journal Editors for authorship for this manuscript, take responsibility for the integrity of the work as a whole and have given final approval for the version to be published Received: 21 November 2017

Accepted: 14 March 2018

Citation: European Endocrinology. 2018;14(1):17-23

Corresponding Author: Baptist Gallwitz,

Department of Medicine IV, Eberhard Karls

University of Tübingen, Tübingen, Germany

E: baptist.gallwitz@med.uni-tuebingen.de

Support: The publication of this article was supported by AstraZeneca. The views and opinions expressed are those of the author and do not necessarily reflect those of Astrazeneca.
People with type 2 diabetes mellitus (T2D) have a two- to four-fold increased risk for coronary heart disease compared to those without diabetes, ${ }^{1-3}$ as well as other vascular disorders (consisting of heart failure [HF], cardiac dysrhythmia, sudden death, hypertensive disease, pulmonary embolism, and aortic aneurysm). Heart failure is a particularly common complication of T2D and is associated with poor outcomes. ${ }^{4,5}$ The risk associated with diabetes is higher at younger ages and lower at higher ages. For instance, at the age of 60 years, a patient with T2D and cardiovascular disease (CVD) has a reduced life expectancy of 12 years compared with the general population, according to a study by the Emerging Risk Factors Collaboration (689,300 participants; 91 European cohorts), ${ }^{6}$ and of 2 years at age 67 years in Sweden. ${ }^{3}$ There is, therefore, a need for novel treatments for T2D that not only improve glycaemic control but also reduce the risk of CVD.

Historically, the aim of glucose-lowering therapy in diabetes was to reduce microvascular complications and interventional studies focused on intensive glucose reduction in T2D have only had a minor or no effect in reducing cardiovascular (CV) risk. ${ }^{7-9}$ In 1998, the UK Prospective Diabetes Study (UKPDS) found that a subgroup of obese patients randomised to metformin had a reduction in myocardial infarction (MI). ${ }^{10}$ Metformin has since become the standard first-line drug treatment for T2D. ${ }^{11}$ However, most people taking metformin ultimately require intensified treatment due to disease progression and insufficient glycaemic control. In the last two decades, numerous therapeutic options have emerged for T2D, including dipeptidyl peptidase 4 inhibitors (DPP-4i), glucagon-like peptide 1 (GLP-1) receptor agonists and sodium-glucose cotransporter 2 (SGLT2) inhibitors.

In 2008, following the withdrawal of rosiglitazone from the market because of its association with increased risk of $\mathrm{HF}$ and $\mathrm{MI}^{12}$ the US Food and Drug Administration (FDA) mandated CV outcome trials (CVOTs) on glucose-lowering drugs (GLDS). ${ }^{13}$ In 2012, the European Medicines Agency (EMA) also published a guideline requiring CVOTs for new GLDS for which specific CV claims are made or that are suspected of having detrimental $\mathrm{CV}$ effects..$^{14} \mathrm{As}$ a result, two drugs - empagliflozin (an SGLT2 inhibitor) and liraglutide (a GLP-1 receptor agonist) - have a level A recommendation in the American Diabetes Association (ADA) 2018 Standards of Medical Care in Diabetes. ${ }^{15}$ This article discusses the findings of the two completed CVOTs on SGLT2 inhibitors to date, their applicability to real-world clinical practice, and the findings of real-world studies that included patients with T2D with a broader $\mathrm{CV}$ risk profile. 


\section{Cardiovascular outcome trials on sodium- glucose cotransporter 2 inhibitors}

Early CVOTs of saxagliptin, ${ }^{16}$ alogliptin, ${ }^{17}$ sitagliptin ${ }^{18}$ and lixisenatide ${ }^{19}$ demonstrated the safety of GLDS but did not show superiority in CV outcomes compared with placebo. In 2015 the Empagliflozin Cardiovascular Outcome Event Trial in Type 2 Diabetes Mellitus Patients (EMPA-REG OUTCOME), ${ }^{20}$ showed a $38 \%$ relative risk reduction in CV death (hazard ratio [HR], 0.62; 95\% confidence interval [Cl], 0.49-0.77; $p<0.001$ ) and a $32 \%$ relative risk reduction in all-cause mortality $(\mathrm{HR}, 0.68 ; 95 \% \mathrm{Cl}$, $0.57-0.82$, p<0.001), as well as a 55\% reduction in HF hospitalisations (HR, $0.65 ; 95 \% \mathrm{Cl}, 0.50-0.85 ; \mathrm{p}=0.002)$. The effects were similar for both doses of empagliflozin, $10 \mathrm{mg}$ or $25 \mathrm{mg}$ once daily. These were surprising and unprecedented findings and attracted considerable attention. The EMPAREG OUTCOME study involved 7,020 patients with T2D and established CVD who were on standard-of-care medications for both hypertension and dyslipidaemia. The size of the effect and the rapid onset of action of empagliflozin were almost certainly not due to glucose lowering, and prompted questions about its underlying cardioprotective actions, and whether the reported CVD benefits were intrinsic to empagliflozin or represented a class effect common to all SGLT2 inhibitors. In addition, EMPA-REG OUTCOME involved predominantly older patients with long-standing diabetes and 99\% with a prior CVD event (MI, stroke, amputation, multivessel coronary artery disease, or coronary artery bypass graft), including HF in $10 \%$ of subjects. This led to speculation about the potential $\mathrm{CV}$ benefits of empagliflozin in lower risk patients.

As a class, the SGLT2 inhibitors - empagliflozin, dapagliflozin and canagliflozin are currently approved by the FDA and EMA although others are in clinical development - share the same mechanism of action. They all decrease renal reabsorption of glucose and induce an increase in glycosuria (Table 1). ${ }^{21-23}$ Approximately $90 \%$ of filtered glucose is absorbed by SGLT2 with the remaining $10 \%$ absorbed by SGLT1..$^{23}$ By inhibiting this process, SGLT2 inhibitors reduce renal glucose reabsorption, increase urinary glucose excretion and reduce serum glucose concentration. They also affect several CV risk factors, including lowering glucose and blood pressure (BP), altering fasting lipid parameters, decreasing arterial stiffness, weight and visceral adiposity, and decreasing albuminuria and serum uric acid levels (Table 1). ${ }^{21,24-30}$ No significant differences have been observed in glucose lowering, body weight loss, and BP reduction among the individual SGLT2 inhibitors. ${ }^{21}$ It has also been suggested that treatment with SGLT2 inhibitors ameliorates oxidative stress ${ }^{31}$ and encourages a shift in fuel metabolism from fatty acids to beta-hydroxybutyrate in the heart, as well as other organs. ${ }^{32}$ Other hypotheses focus on the potential haemodynamic benefits including reduced pre- and afterload, enhanced myocardial oxygen supply and potential improvements of SGLT2 inhibitors in cardiac systolic and diastolic function. ${ }^{33}$ An additional interesting hypothesis is that empagliflozin reduces sodium and calcium overload in the myocardial cell and increases concentration of calcium in the myocardial mitochondria and thereby reducing HF development. ${ }^{34}$ If the observed $\mathrm{CV}$ benefits are related to the glucuretic/natriuretic effect and subsequent volume depletion together with reduction of systolic BP or via metabolic effects, they are likely to be common to all SGLT2 inhibitors. However, different drugs may have different specificity for SGLT2 and SGLT1, ${ }^{35}$ as well as different benefit/risk profiles, therefore it is impossible to draw conclusions based on the EMPA-REG OUTCOME study alone.

The Canagliflozin Cardiovascular Assessment Study (CANVAS-PROGRAM) was published in June 2017 (Table 2). ${ }^{36}$ The rate of the primary endpoint, a composite of death from cardiovascular causes, nonfatal MI, or nonfatal stroke, was significantly lower with canagliflozin than with placebo for
Table 1: Cardiovascular effects of sodium-glucose cotransporter 2 inhibitors based on clinical and mechanistic studies

\begin{tabular}{|l|l|}
\hline CV effect & Reference \\
\hline Blood pressure $\downarrow$ & 26,27 \\
\hline Arterial stiffness $\downarrow$ & 30 \\
\hline Glucose and insulin $\downarrow$ & 26,28 \\
\hline Albuminuria $\downarrow$ & 27 \\
\hline Uric acid $\downarrow$ & 21,26 \\
\hline Weight $\downarrow$ & 29 \\
\hline Visceral adiposity $\downarrow$ & 29 \\
\hline Oxidative stress $\downarrow$ & 31 \\
\hline Triglycerides $\downarrow$ & 25,26 \\
\hline LDL-C $\uparrow$ & 24,25 \\
\hline HDL-C $\uparrow$ & $25,26,28$ \\
\hline
\end{tabular}

$C V=$ cardiovascular; $H D L-C=$ high density lipoprotein cholesterol; $L D L-C=10$ w density lipoprotein cholesterol; SNS = sympathetic nervous system.

both doses pooled (26.9 versus 31.5 participants per 1000 patientyears; HR $0.86 ; 95 \% \mathrm{Cl}, 0.75-0.97 ; \mathrm{p}<0.001$ for noninferiority; $\mathrm{p}=0.02$ for superiority). While these data suggest that a class effect of SGLT2 inhibitors is likely, unlike in EMPA-REG OUTCOME the reductions in the individual end points of all-cause and cardiovascular death were not significant in CANVAS-PROGRAM, although the point-estimates were in the same direction as in the EMPA-REG OUTCOME. One possible explanation for this is that, while almost all of the EMPA-REG OUTCOME subjects had established CVD, approximately 20\% of the CANVASPROGRAM were at increased risk for cardiovascular events and around two-thirds had no prior history of CVD and were accordingly at lower CV-risk and event rates, reducing the statistical power. However, there were some notable differences between the safety findings of the two trials, with an increased risk of amputation with canagliflozin (6.3 versus 3.4 participants per 1000 patient-years; HR, 1.97; 95\% Cl, 1.412.75); amputations were primarily at the level of the toe or metatarsal. This was an unexpected finding, raising the question of whether it was a random finding or compound-specific, suggesting that important differences may exist between the SGLT2 inhibitors, and requires further investigation.

The ongoing large CV outcome trial Dapagliflozin Effect on Cardiovascular Events (DECLARE)-Thrombolysis in Myocardial Infarction (TIMI)-58 is investigating the effect of dapagliflozin on CV outcomes in a broad population of patients with either established CVD $(40 \%$ have had a prior CV event) or multiple CV risk factors, with an estimated completion date of 2019 and will give further answers to the effect of SGLT2 inhibitors in a low risk T2D population and whether a class effect exists (NCT01032629).

\section{Meta-analyses}

A recent meta-analysis and systematic review included data from six regulatory submissions $(n=37,525)$ and 57 clinical trials $(n=33,385)$ and involved seven different SGLT2 inhibitors. The SGLT2 inhibitors were found to reduce the risk of major adverse CV events (MACE; relative risk 0.84 [95\% $\mathrm{Cl} 0.75-0.95] ; \mathrm{p}=0.006$ ), CV death (relative risk 0.63 [0.51-0.77]; $p<0.0001), H F(0.65$ [0.50-0.85]; $p=0.002)$, and death from any cause (relative risk 0.71 [0.61-0.83]; $p<0.0001$ ). While the efficacy results were largely driven by empagliflozin, results for other SGLT2 inhibitors were not clearly different, supporting the hypothesis that that the CV benefits of SGLT2 inhibitors are consistent across the drug class. ${ }^{37}$ In addition, a 
Table 2: Summary of key studies investigating the cardiovascular effects of sodium-glucose cotransporter 2 inhibitors

\begin{tabular}{|c|c|c|c|c|c|}
\hline Study & Study type & Patient population & Inclusion criteria & Exclusion criteria & Key findings \\
\hline \multicolumn{6}{|l|}{ CVOT } \\
\hline $\begin{array}{l}\text { EMPA-REG } \\
\text { OUTCOME }^{20}\end{array}$ & $\begin{array}{l}\text { Phase III clinical } \\
\text { trial }\end{array}$ & $\begin{array}{l}n=7,020 ;>99 \% \text { had } \\
\text { established CVD }\end{array}$ & $\begin{array}{l}\text { Diagnosis of T2D prior to } \\
\text { informed consent } \\
\text { Male or female patients on } \\
\text { diet and exercise regimen } \\
\text { who are drug-naive or pre- } \\
\text { treated with any background } \\
\text { therapy. Antidiabetic therapy } \\
\text { has to be unchanged for } 12 \\
\text { weeks prior to randomization. } \\
\text { HbA1C of } \geq 7.0 \% \text { and } \leq 10 \% \\
\text { for patients on background } \\
\text { therapy or HbA1c } \geq 7.0 \% \text { and } \\
\leq 9.0 \% \text { for drug naive patients } \\
\text { Age } \geq 18 \text { years } \\
\text { BMl } \leq 45 \text { at visit one } \\
\text { Signed and dated informed } \\
\text { consent } \\
\text { High CV risk }\end{array}$ & 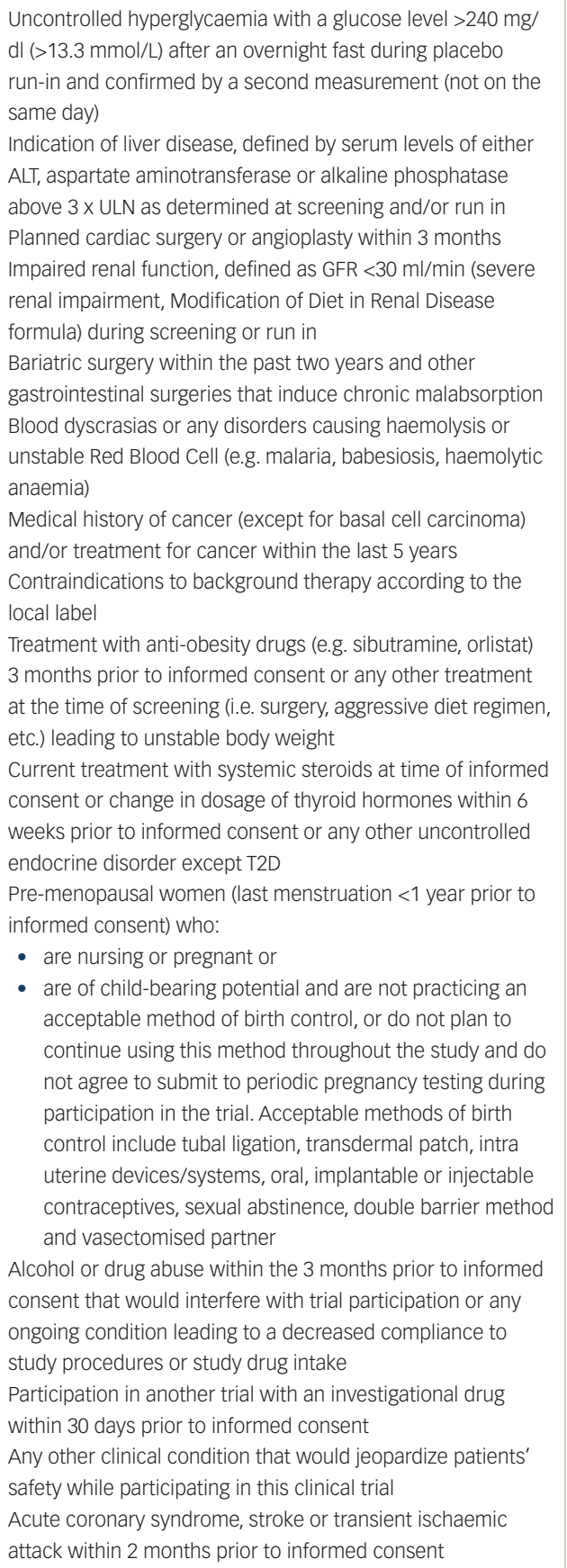 & $\begin{array}{l}\text { 14\% reduction } \\
\text { composite of death } \\
\text { from CV causes, } \\
\text { nonfatal MI, or nonfatal } \\
\text { stroke for canagliflozin } \\
\text { versus placebo; 38\% risk } \\
\text { reduction in CV death, } \\
35 \% \text { reduction in heart } \\
\text { failure hospitalisation } \\
\text { and } 32 \% \text { risk reduction } \\
\text { in all-cause mortality }\end{array}$ \\
\hline $\begin{array}{l}\text { CANVAS- } \\
\text { PROGRAM }{ }^{36}\end{array}$ & $\begin{array}{l}\text { Phase III clinical } \\
\text { trial }\end{array}$ & $\begin{array}{l}n=10,142 ; 65.6 \% \\
\text { had a history of } \\
\text { CVD }\end{array}$ & $\begin{array}{l}\text { Patients must have a diagnosis } \\
\text { of T2D and } \geq 30 \text { years old with } \\
\text { history of } \mathrm{CV} \text { event, or } \geq 50 \\
\text { years old with high risk of CV } \\
\text { events } \\
\text { Patients must have inadequate } \\
\text { diabetes control (as defined } \\
\text { by glycosylated haemoglobin } \\
\text { greater than or equal to } 7.0 \% \\
\text { to less than or equal to } 10.5 \% \\
\text { at screening) and be either } \\
\text { not currently on diabetes drug } \\
\text { therapy or on therapy with any } \\
\text { approved class of diabetes } \\
\text { drugs }\end{array}$ & $\begin{array}{l}\text { A history of diabetic ketoacidosis, T1D, pancreas or beta-cell } \\
\text { transplantation, or diabetes secondary to pancreatitis or } \\
\text { pancreatectomy } \\
\text { History of one or more severe hypoglycaemic (i.e. very low } \\
\text { blood sugar) episode within } 6 \text { months before screening }\end{array}$ & $\begin{array}{l}\text { 14\% relative risk } \\
\text { reduction in composite } \\
\text { of death from CV } \\
\text { causes, nonfatal Ml, } \\
\text { or nonfatal stroke for } \\
\text { canagliflozin versus } \\
\text { placebo }\end{array}$ \\
\hline
\end{tabular}




\begin{tabular}{|c|c|c|c|c|c|}
\hline Study & Study type & Patient population & Inclusion criteria & Exclusion criteria & Key findings \\
\hline $\begin{array}{l}\text { DECLARE } \\
\text { TIMI-58 }\end{array}$ & $\begin{array}{l}\text { Phase III clinical } \\
\text { trial }\end{array}$ & $\begin{array}{l}n=17,276 ; \\
\text { established CVD } \\
\text { ( } 40 \% \text { have had a } \\
\text { prior CV event) or } \\
\text { multiple CV risk } \\
\text { factors }\end{array}$ & $\begin{array}{l}\text { Provision of informed consent } \\
\text { prior to any study specific } \\
\text { procedures } \\
\text { Female or male aged } \geq 40 \\
\text { years } \\
\text { Diagnosed with T2D } \\
\text { High risk for CV events }\end{array}$ & $\begin{array}{l}\text { Diagnosis of T1D } \\
\text { History of bladder cancer or history of radiation therapy to the } \\
\text { lower abdomen or pelvis at any time } \\
\text { Chronic cystitis and/or recurrent urinary tract infections } \\
\text { Pregnant or breast-feeding patients }\end{array}$ & Results not available yet \\
\hline \multicolumn{6}{|c|}{ Meta-analyses of RCTs } \\
\hline $\begin{array}{l}\text { Meta-analysis } \\
\text { of all SLGT2 } \\
\text { inhibitors }^{37}\end{array}$ & Meta-analysis & $n=70,910$ & & & $\begin{array}{l}16 \% \text { relative risk } \\
\text { reduction in MACE, 37\% } \\
\text { reduction in CV death }\end{array}$ \\
\hline $\begin{array}{l}\text { Meta-analysis of } \\
\text { dapagliflozin }{ }^{38}\end{array}$ & Meta-analysis & $n=9,339$ & & & $\begin{array}{l}\text { 23\% relative risk } \\
\text { reduction in MACE }\end{array}$ \\
\hline \multicolumn{6}{|c|}{ Real-world evidence } \\
\hline CVD-REAL ${ }^{46}$ & $\begin{array}{l}\text { Real-world } \\
\text { observational } \\
\text { study }\end{array}$ & $\begin{array}{l}\mathrm{n}=309,056 ; 87 \% \\
\text { did not have a } \\
\text { history of CVD }\end{array}$ & $\begin{array}{l}\text { New user receiving or } \\
\text { dispensed prescription of } \\
\text { SGLT2 inhibitor medication or } \\
\text { other glucose lowering drug, } \\
\text { oral as well as injectable, } \\
\text { including FDC products } \\
\text { containing these medication } \\
\text { groups } \\
\text { T2D diagnosis on or prior to } \\
\text { the index date } \\
\geq 18 \text { years old at index date } \\
>1 \text { year of data history in the } \\
\text { database prior to the index } \\
\text { date }\end{array}$ & $\begin{array}{l}\text { Patients with a T1D diagnosis } \\
\text { Patients with gestational diabetes within } 1 \text { year before index } \\
\text { date }\end{array}$ & $\begin{array}{l}39 \% \text { reduced risk of HF } \\
\text { hospitalisation, } 51 \% \\
\text { lower risk of all-cause } \\
\text { death in patients taking } \\
\text { SGLT2 inhibitors }\end{array}$ \\
\hline $\mathrm{THIN}^{49}$ & $\begin{array}{l}\text { Real-world } \\
\text { observational } \\
\text { study }\end{array}$ & $\begin{array}{l}\mathrm{n}=22,124 ; 20 \% \\
\text { had a previous CV } \\
\text { event }\end{array}$ & $\begin{array}{l}\text { Aged } 18+\text { years at the index } \\
\text { date, } \\
\text { A diagnosis of } T 2 D \text { any time } \\
\text { before the index date } \\
\text { had been initiated } \\
\text { treatment with dapagliflozin, } \\
\text { remained at their practice at } \\
\text { least } 3 \text { months after } \\
\text { treatment initiation }\end{array}$ & Patients with a T1D diagnosis & $\begin{array}{l}50 \% \text { lower risk of all- } \\
\text { cause death }\end{array}$ \\
\hline $\begin{array}{l}\text { Swedish } \\
\text { registry50 }\end{array}$ & $\begin{array}{l}\text { Real-world } \\
\text { observational } \\
\text { study }\end{array}$ & $\begin{array}{l}n=37,603 ; C V D \\
\text { in } 33 \%\end{array}$ & $\begin{array}{l}\text { A diagnosis of T2D } \\
\text { Prescription for either DPP-4i- } \\
\text { or SGLT2i, or insulin, } 1 \text { July } \\
2013 \text { to } 31 \text { December } 2014\end{array}$ & $\begin{array}{l}\text { Patients with a diagnosis of gestational diabetes. } \\
\text { Within one year of the index date } \\
\text { Patients with T1D were excluded }\end{array}$ & $\begin{array}{l}56 \% \text { reduced risk of } \\
\text { all-cause mortality and } \\
49 \% \text { reduced risk of } \\
\text { CVD with dapagliflozin } \\
\text { versus insulin }\end{array}$ \\
\hline
\end{tabular}

ALT = alanine aminotransferase; $B M I=$ body mass index; CANVAS-PROGRAM = Canagliflozin Cardiovascular Assessment Study; CV = cardiovasCular; $C$ VVD = cardiovasCular disease; $C V D-R E A L=$ Comparative Effectiveness of Cardiovascular Outcomes in New Users of SGLT-2 Inhibitors; CVOT= CardiovasCular outcome trial; DECLARE = Dapagliflozin Effect on CardiovascuLAR Events; DPP-4i = dipeptidyl peptidase-4 inhibitors; EMPA-REG OUTCOME = Empagliflozin Cardiovascular Outcome Event Trial in Type 2 Diabetes Mellitus Patients; FDC = fixed-dose combinations; GFR = glomerular filtration rate; $H$ bA1C = glycosylated haemoglobin; $H F=$ heart failure; $M A C E=$ major adverse cardiac events; $\mathrm{MI}=$ myocardial infarction; $R C T$ = randomised controlled trial; SGLT2 = sodium-glucose cotransporter 2; SGLT2i = sodium-glucose cotransporter 2 inhibitor; T1D = type 1 diabetes; T2D = type 2 diabetes; TIMI = Thrombolysis in Myocardial Infarction; THIN = The Health Improvement Network; ULN = upper limit of normal.

meta-analysis investigating the CV safety of dapagliflozin analysed data from 21 clinical trials $(n=9,339)$, including five phase Ilb studies of 12 to 24 weeks duration and 16 phase III studies of up to 208 weeks duration. At baseline, 3,214 patients (34.4\%) had a history of CVD (coronary artery disease, cerebrovascular disease, peripheral vascular disease or congestive HF). The results showed that dapagliflozin was not associated with increased $\mathrm{CV}$ risk and may have a beneficial effect both in the overall population, although confidence limits were overlapping 1.00 (HR 0.77; 95\% Cl 0.54-1.10 for MACE) and in those with a history of CVD (HR 0.80; 95\% Cl 0.53-1.22). ${ }^{38}$ These results are consistent with meta-analyses of the CV effect of other SGLT2 inhibitors. ${ }^{39}$

\section{Real-world evidence}

As analytical tools continue to grow in power and sophistication, real-world evidence is an important component of pharmaceutical product development and is increasingly used to support regulatory decision-making. 11,40-42 Real-world studies are considered statistically less rigorous than randomised controls and may have inadvertent biases. Two important forms of bias in this respect that may lead to overestimation of differences between two treatment strategies are the so-called immortal time bias and the time-lag bias. ${ }^{43}$ Furthermore, there can be differences between studies in clinical practice and the quality and detail of the data, making studies hard to interpret. ${ }^{44}$ Despite these limitations, however, real-world data have the potential to improve clinical outcomes by increasing the understanding of how best to incorporate new therapies into everyday clinical practice. These data help fill the knowledge gap between clinical trials and actual clinical practice. ${ }^{45}$ While clinical trials remain the gold standard for drug approval, real-world studies can provide valuable information on how drugs perform within specific subgroups often excluded in clinical trials (age, gender, differences in disease severity, comorbidities, differences in therapeutic adherence). Real-world studies are useful for assessing long-term response and safety, as well as for generating hypotheses to guide future clinical directions. 
Four recent real-world studies have added to the body of evidence in support of the hypothesis that SGLT2 inhibitors exert their CV benefits via a class effect (Table 2). The Comparative Effectiveness of Cardiovascular Outcomes in New Users of SGLT-2 Inhibitors (CVD-REAL) study is the first large real-world study of patients with T2D. ${ }^{46}$ It collected real-world data from six countries and more than 300,000 patients, $87 \%$ of whom did not have a history of CVD. Inclusion criteria were new users receiving a SGLT2 inhibitor or other GLDS with established T2D on or prior to the index date, age $\geq 18$ years and availability of $>1$ year (6 months in Germany) historical data prior to the index date. The study period and inclusion of patients was 2012-2015, thus in large part before the publication of the EMPA-REG OUTCOME study and not influenced by the results or inclusion criteria in that study. Patients in the SGLT2 inhibitor and GLD groups were matched by propensity score analysis. In the primary analysis, patients prescribed SGLT2 inhibitors had a 39\% lower associated risk for HF hospitalisation compared with other GLDs (HR 0.61, p<0.001). For all analyses (multivariable adjusted, intention to treat, stepwise removal of thiazolidinedione, insulin and sulfonylurea from the control group), SGLT2 inhibitors showed lower incidences of HF hospitalisations than other GLDS $(p<0.001)$. In addition, patients in the SGLT2 inhibitor group had lower associated risk of all-cause death compared with other GLDS (HR 0.49, p<0.001). ${ }^{46}$

One limitation of the CVD-REAL study was that other CV events such as $\mathrm{Ml}$ and stroke were not examined, however HF is the most common CV comorbidity in T2D. ${ }^{4}$ Importantly, there was no significant heterogeneity in findings across countries, despite geographic variations in the use of SGLT2 inhibitors (76\% canagliflozin in the US and 92\% dapagliflozin in Europe, with empagliflozin accounting for $<7 \%$ of total exposure time; Figure 1). Furthermore, there is no information of the dose distribution of the patients treated with canagliflozin and empagliflozin. ${ }^{46}$ These findings suggest that the observed CV benefits are likely to be class related. The benefits in terms of HF hospitalisation and all-cause mortality were strikingly similar to those reported in EMPA-REG OUTCOME (where both doses of empagliflozin had very similar effects), suggesting that the benefits translate to real-world clinical practice. In addition, the study involved a broad population of patients with T2D, the majority (87\%) of whom did not have known CVD, suggesting that the benefits of SGLT2 inhibitors might extend to those with a lower risk of CVD. The CVD-REAL study thus suggests that the beneficial effects of SGLT2 inhibitors may be extended to broader and lower risk group of patients with T2D than previously evaluated in clinical trials.

The CVD-REAL Nordic study identified all patients with T2D who were prescribed GLDs between 2012 and 2015 from the Prescribed Drug Registries and linked them with the National Patient Registry and Cause of Death Registry in Denmark, Norway and Sweden $(n=91,320)$. This represented a broad T2D population and included 25\% with prior registered established CVD. New use of SGLT2 inhibitors was associated with lower risk of MACE compared to new use of another GLD, and in a similar magnitude as in the EMPA-REG OUTCOME and CANVAS-PROGRAM. ${ }^{47}$

Recently the CVD-REAL Nordic study group presented data showing that, compared with new use of DPP-4i, new use of dapagliflozin was associated with lower risk for HF hospitalisation (HR 0.62; $95 \% \mathrm{Cl}, 0.50-$ $0.77 \mathrm{p}<0.001$ ); MACE (HR 0.79; $95 \% \mathrm{Cl}, 0.67-0.94 ; \mathrm{p}=0.006$ ); and all-cause mortality ( $\mathrm{HR} 0.59 ; 95 \% \mathrm{Cl}, 0.49-0.72 \mathrm{p}=0.004$ ). ${ }^{48}$ Again, these findings were similar to those in EMPA-REG OUTCOME but in contrast to a placebo as a comparator, the comparator was single group of compounds with CV-safe data - the DPP-4i.

\section{Figure 1: The CVD-REAL study}

Contribution of the sodium-glucose cotransporter 2 inhibitor class as a proportion of exposure time in the propensity-match cohorts

A. All countries combined

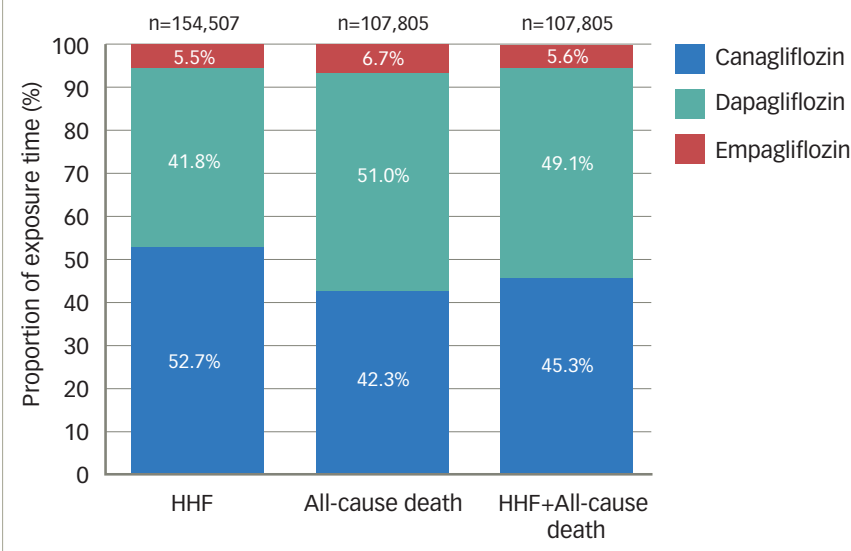

B. US only

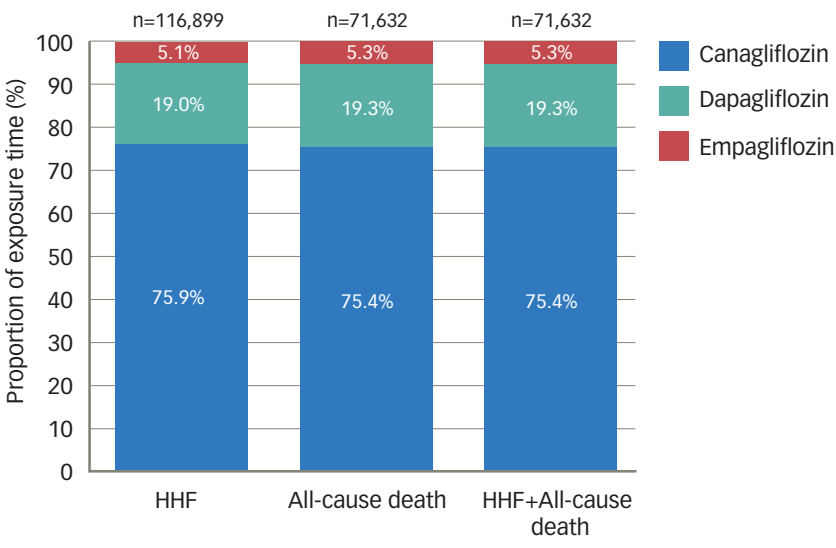

C. European countries combined

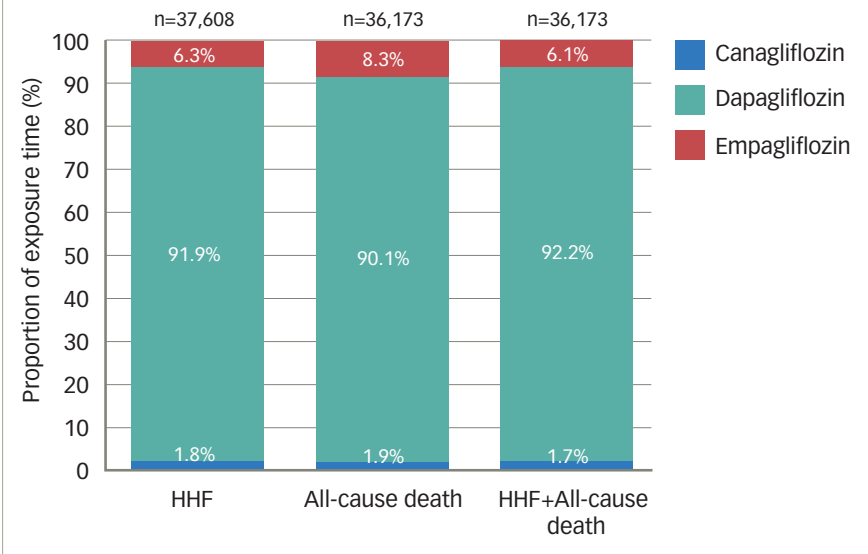

Reproduced under an open access license from Kosiborod et al., 2017.46 $H H F=$ hospitalisation for heart failure; SGLT2 = sodium-glucose cotransporter-2.

Another study investigated all-cause mortality in patients with T2D taking dapagliflozin from The Health Improvement Network (THIN) database. This was a UK population-based, retrospective open cohort study $(n=22,124)$ that compared outcomes in patients with T2D taking dapagliflozin with matched controls with T2D who were taking other GLDS. ${ }^{49}$ The study included any patient administered dapagliflozin at any time point between 1 January 2013 and 1 september 2015. Inclusion criteria were: age $\geq 18$ years at the index date, a diagnosis of $\mathrm{T} 2 \mathrm{D}$, having being registered at their practice at a year prior to treatment initiation and to remain at the practice for at least 3 months 
after treatment initiation. The mean age of participants was 58.4 years and the mean duration of diabetes was approximately 9 years. Approximately $20 \%$ of the study population $(n=4,350)$ had a previous CV event (ischaemic heart disease, stroke and/or HF).

Data from THIN over a median observation period of 1 year showed that all-cause mortality was significantly lower in patients taking dapagliflozin than those taking other GLDs (adjusted incidence rate ratio [IRR] 0.50, $95 \% \mathrm{Cl}: 0.33-0.75, \mathrm{p}=0.001$ ), similar to the mortality reductions reported in EMPA-REG OUTCOME. ${ }^{49}$ The risk of all-cause mortality was also lower in patients taking dapagliflozin in the low CV risk population, (IRR 0.44 , $95 \% \mathrm{Cl}: 0.25-0.78, p=0.002$ ). The low risk population was defined as the absence of all CVD outcomes (MI and ischaemic heart disease, stroke and transient ischaemic attack [TIA] and HF) at baseline. Although showing a similar numerical trend, no significant difference in the risk of $\mathrm{CV}$ events was detected between low risk patients who received dapagliflozin and matched controls receiving GLDS. This observational study therefore suggested that the CV benefits of empagliflozin in the EMPA-REG OUTCOME study are seen with dapagliflozin in both high as well as low risk patients.

A report of a Swedish registry study that investigated the association of oral GLDS, compared with that of insulin, with the risk of all-cause mortality, CVD and severe hypoglycaemia has also been published recently. ${ }^{50}$ The study included all patients with T2D who were new users of either DPP-4i or SGLT2 inhibitors (only dapagliflozin was available in Sweden during the study period) during 2013-2014. Of 37,603 participants, 21,758 were matched 1:1 to DPP-4i/dapagliflozin versus insulin groups, with median follow-up times of 1.51 years and 1.53 years respectively. The DPP-4i/dapagliflozin group was associated with a reduced risk of all-cause mortality, CVD and hypoglycaemia compared to the insulin group (HR [95\% Cl] 0.56 [0.49-0.64]), 0.85 [0.73-0.99] and 0.26 [0.12-0.57] respectively. In separate analyses for the two drug classes, dapagliflozin was associated with lower risks of both all-cause mortality and CVD (HR 0.44 [0.28-0.70]) and 0.51 [0.30-0.86]) respectively, while DPP-4i use was associated with lower risk of all-cause mortality (HR 0.59 [0.51-0.67]), but not with CVD (HR 0.87 [0.75-1.01])..$^{50}$

Finally, another recently published retrospective cohort study in the US (118,018 new users of SGLT2 inhibitors, including 73,024 taking canagliflozin) found no evidence of increased risk of below-knee lower extremity amputation for new users of canagliflozin compared with non-SGLT2 inhibitor antihyperglycaemic agents in a broad population of patients with T2D. ${ }^{1}$

\section{Clinical implications of the totality of evidence}

The findings of EMPA-REG OUTCOME are potentially paradigm changing, for the first time showing a reduction in CV events and mortality in patients with T2D with established CVD and have already influenced diabetes and cardiovascular guidelines. ${ }^{52-54}$ The recent CANVAS-
PROGRAM data suggest that the cardiovascular benefits observed in EMPA-REG OUTCOME is likely to be a class effect, and its broader inclusion criteria suggests that the CV benefits of SGLT2 inhibitors may extend to lower risk patients. Real-world studies have further extended the inclusion criteria of the EMPA-REG OUTCOME and CANVASPROGRAM. These data suggest that the CV benefits of SGLT2 inhibitors may also be applicable to the general diabetic population, not only those with established CVD, a finding that should be confirmed in a clinical trial setting. The CVD-REAL data were consistent across countries although there was considerable heterogeneity of use of specific SGLT2 inhibitors, adding to the body of evidence in favour of a class effect. Of note, the results of CVD-REAL were unchanged after the sequential removal of several GLD classes from the comparator group, suggesting that the findings reflect the beneficial effects of SGLT2 inhibitors rather than adverse effects of comparator GLDS. ${ }^{55} \mathrm{~A}$ major limitation so far with real life data is the limited information on safety data and future real life analyses should also include such information. However, data from the DECLARE study is needed before any firm conclusions about a class effect can be made.

\section{Summary and concluding remarks}

Reduction of cardiovascular complications has become an important treatment goal in T2D and for the first time there are licensed GLDs that also reduce $\mathrm{CV}$ event and mortality. ${ }^{20,36,56,57}$ While it must be emphasized that only empagliflozin is currently recommended by the ADA for CV risk reduction, the totality of evidence from EMPA-REG OUTCOME, CANVASPROGRAM and real-world studies suggest that the CV benefits observed with empagliflozin in the EMPA-REG OUTCOME study may be a class effect. There are some signals on increased risk of amputations with canagliflozin in the CANVAS-PROGRAM study that should be considered in high risk patients. However, in the absence of data from the ongoing prospective DECLARE study, it is not possible to conclude that a class effect exists. Individualisation remains the cornerstone for selection of therapy for hyperglycaemia in T2D.

Results from the CVD-REAL and THIN databases have demonstrated that data derived from rigorous, large international epidemiologic studies are a valuable addition to those generated by clinical trials, as they suggest effectiveness of treatments outside the limitation of the inclusion and exclusion criteria in randomised controlled trials and in a broader patient population, that is more representative of those seen in primary care. It is important to note that retrospective studies have inherent limitations, possibility of selection bias and residual confounding and relatively short follow-up. Moreover, SGLT2 inhibitors have been used in real-world practice for a relatively limited time and long-term follow up will be needed to determine whether the observed CV benefits are sustained. There is also a need for further studies examining the mechanisms underlying the CV benefits of SGLT2 inhibitors although CV-mortality-preventive and CV-safe treatment should not be withheld awaiting such explanatory findings. $]$
1. Emerging Risk Factors Collaboration, Sarwar N, Gao P, et al. Diabetes mellitus, fasting blood glucose concentration, and
risk of vascular disease: a collaborative meta-analysis of 102 prospective studies. Lancet. 2010;375:2215-22.

2. Shah AD, Langenberg C, Rapsomaniki E, et al. Type 2 diabetes and incidence of cardiovascular diseases: a cohort study in 1.9 million people. Lancet Diabetes Endocrinol. 2015;3:105-13.

Norhammar A Bodegård J. Nyström T et al. Incidence,

Norhammar A, Bodegard J, Nystrom T, et al. Incidence,
prevalence and mortality of type 2 diabetes requiring glucoseprevalence and mortality of type 2 diabetes requiring glucose-
lowering treatment, and associated risks of cardiovascular complications: a nationwide study in Sweden, 2006-2013. complications: a nationwide study in

Diabetologia. 2016;59:1692-701.

4. Cavender MA, Steg PG, Smith SC, Jr., et al. Impact of diabetes mellitus on hospitalization for heart failure, cardiovascular events, and death: outcomes at 4 years from the Reduction of Atherothrombosis for Continued Health (REACH) registry.
Circulation. 2015;132:923-31.

Johansson I, Edner M, Dahlström U, et al. Is the prognosis in patients with diabetes and heart failure a matter of unsatisfactory management? An observational study from the swedish Heart Failure Regist

Emerging Risk Factors Collaboration, Di Angelantonio E, Kaptoge $S$, et al. Association of cardiometabolic multimorbidity with mortality JAMA. 2015;314:52-60.

7. Wh mortily. JAMA. 2015:314:52-60. Gerstein HC, Miller ME, et al. Effects of intensive glucose lowering in type 2 diabetes. N Eng/ J Med. 2008;358:2545-5 8. ADVANCE Collaborative Group, Patel A, MacMahon S, et al. Intensive blood glucose control and vascular outcomes in patients with type 2 diabetes. N Eng/ J Med. 2008;358:2560-72.

9. UK Prospective Diabetes Study (UKPDS) Group. Intensive bloodglucose control with sulphonylureas or insulin compared with conventional treatment and risk of complications in patients with type 2 diabetes (UKPDS 33). Lancet. 1998:352:837-53.

10. UK Prospective Diabetes Study (UKPDS) Group. Effect of intensive blood-glucose control with metformin on complications in overweight patients with type 2 diabetes (UKPDS 34). Lancet. 1998;352:854-65.

11. Garrison LP, Jr., Neumann PJ, Erickson P, et al. Using real-world data for coverage and payment decisions: the ISPOR Realdata for coverage and payment decisions: the ISPOR Real-

12. Singh S, Loke YK, Furberg CD. Long-term risk of cardiovascular events with rosiglitazone: a meta-analysis. JAMA. 2007;298:1189-95

13. FDA. Guidance for Industry - Diabetes Mellitus - Evaluating Cardiovascular Risk in New Antidiabetic Therapies to Treat Type 2 Diabetes. 2008. Available at: www.fda.gov/downloads/ drugs/guidancecomplianceregulatoryinformation/guidances/ 
ucm071627.pdf (accessed 14 February 2017).

14. European Medicines Agency. Guideline on clinical investigation of medicinal products in the treatment or prevention of diabetes mellitus. 2012. Available at: http://www.ema. europa.eu/docs/en GB/document_library/Scientific europa.eu/docs/en_GB/document_library/Scientific_.
guideline/2012/06/WC500129256.pdf (accessed 14 February guidelin).

15. American Diabetes Association. 9. Cardiovascular Disease and Risk Management: Standards of Medical Care in Diabetes-2018 Diabetes Care. 2018;41:S86-104

16. Scirica BM, Bhatt DL, Braunwald E, et al. Saxagliptin and cardiovascular outcomes in patients with type 2 diabetes mellitus. N Eng/ J Med. 2013;369:1317-26.

17. White WB, Cannon $\mathrm{CP}$, Heller $\mathrm{SR}$, et al. Alogliptin after acute coronary syndrome in patients with type 2 diabetes. N Eng/ Med. 2013;369:1327-35

18. Green JB, Bethel MA, Armstrong PW, et al. Effect of sitagliptin on cardiovascular outcomes in type 2 diabetes. N EngI I Med. 2015;373:232-42.

19. Pfeffer MA, Claggett $B$, Diaz $R$, et al. Lixisenatide in patients with type 2 diabetes and acute coronary syndrome. N Eng/ I Med. 2015:373:2247-57.

20. Zinman B, Wanner C, Lachin JM, et al. Empagliflozin, cardiovascular outcomes, and mortality in type 2 diabetes. $N$ Eng/ J Med. 2015;373:2117-28.

21. Rosenstock J, Aggarwal N, Polidori D, et al. Dose-ranging effects of canagliflozin, a sodium-glucose cotransporter 2 inhibitor, as add-on to metformin in subjects with type 2 diabetes. Diabetes Care. 2012;35:1232-8

22. Marsenic 0 . Glucose control by the kidney: an emerging target in diabetes. Am J Kidney Dis. 2009:53:875-83.

23. Bays H. Sodium glucose co-transporter type 2 (SGLT2) inhibitors: targeting the kidney to improve glycemic control in diabetes mellitus. Diabetes Ther. 2013;4:195-220.

24. Inzucchi SE, Zinman B, Wanner C, et al. SGLT-2 inhibitors and cardiovascular risk: proposed pathways and review of ongoing outcome trials. Diab Vasc Dis Res. 2015;12:90-100

25. Hardy E, Ptanszynska, A., de Bruin, T.W.A., et al. Changes in lipid profiles of patients with type 2 diabetes mellitus on dapagliflozin therapy. Diabetologia. 2013;56 Suppl.1:S1-566 \#947.

26. Hach T, Gerich, J., Salsali, A., et al. Empagliflozin improves glycaemic parameters and cardiovascular risk factors in patients with type 2 diabetes: pooled data from four pivotal phase III trials. Diabetologie und Stoffwechsel. 2014;9:142.

27. Kohan $D E$, Fioretto $P$, Tang W, List JF. Long-term study of patients with type 2 diabetes and moderate renal impairment shows that dapagliflozin reduces weight and blood pressure but does not improve glycemic control. Kidney Int. 2014;85:962-71.

28. Sinclair A, Bode B, Harris S, et al. Efficacy and safety of canagliflozin compared with placebo in older patients with type 2 diabetes mellitus: a pooled analysis of clinical studies. BMC 2 diabetes mellitus: a pooled

29. Cefalu WT, Leiter LA, Yoon KH, et al. Efficacy and safety of canagliflozin versus glimepiride in patients with type 2 diabetes inadequately controlled with metformin (CANTATA-SU): 52 week results from a randomised, double-blind, phase 3 noninferiority trial. Lancet. 2013;382:941-50.

30. Cherney DZ, Perkins BA, Soleymanlou N, et al. The effect of empagliflozin on arterial stiffness and heart rate variability in subjects with uncomplicated type 1 diabetes mellitus. Cardiovasc Diabetol. 2014;13:28.
31. Terami N, Ogawa D, Tachibana $\mathrm{H}$, et al. Long-term treatment with the sodium glucose cotransporter 2 inhibitor, dapagliflozin, ameliorates glucose homeostasis and diabetic nephropathy in db/db mice. PLOS One. 2014;9:e100777. doi: 10.1371/journal. $\mathrm{db} / \mathrm{db}$ mice. $P L$
pone. 0100777

32. Ferrannini E, Mark M, Mayoux E. CV Protection in the EMPAREG OUTCOME Trial: A "Thrifty Substrate" Hypothesis. Diabetes Care. 2016;39:1108-14

33. Sattar N, McLaren J, Kristensen SL, et al. SGLT2 Inhibition and cardiovascular events: why did EMPA-REG Outcomes surprise and what were the likely mechanisms? Diabetologia. 2016;59:1333-9.

34. Baartscheer A, Schumacher CA, Wust RC, et al. Empagliflozin decreases myocardial cytoplasmic $\mathrm{Na}+$ through inhibition of the cardiac $\mathrm{Na}+/ \mathrm{H}+$ exchanger in rats and rabbits. Diabetologia. 2017;60:568-73.

35. Washburn WN, Poucher SM. Differentiating sodium-glucose co-transporter-2 inhibitors in development for the treatmen of type 2 diabetes mellitus. Expert Opin Investig Drugs. 2013;22:463-86.

36. Neal B, Perkovic V, Mahaffey KW, et al. Canagliflozin and cardiovascular and renal events in type 2 diabetes. N Eng/ $\mathrm{J}$ Med. 2017:377:644-57.

37. Wu JH, Foote C, Blomster J, et al. Effects of sodium-glucose cotransporter-2 inhibitors on cardiovascular events, death, and major safety outcomes in adults with type 2 diabetes: a systematic review and meta-analysis. Lancet Diabetes Endocrinol. 2016;4:411-9.

38. Sonesson C, Johansson PA, Johnsson E, Gause-Nilsson I. Cardiovascular effects of dapagliflozin in patients with type 2 diabetes and different risk categories: a meta-analysis. Cardiovasc Diabetol. 2016;15:37.

39. Monami M, Dicembrini I, Mannucci E. Effects of SGLT2 inhibitors on mortality and cardiovascular events: a comprehensive meta-analysis of randomized controlled trials. comprehensive meta-analysis of

40. FDA. Use of real-world evidence to support regulatory decision-making for medical devices. Guidance for industry and food and drug administration staff. 2017. Available at: https://www.fda.gov/downloads/medicaldevices/ deviceregulationandguidance/guidancedocuments/ ucm513027.pdf (accessed 26 July 2017)

41. European Commission. STAMP Commission Expert Group. Real world evidence. 2016. Available at: https://ec.europa. eu/health//sites/health/files/files/committee/stamp/2016-03 stamp4/4_real_world_evidence_background_paper.pdf (accessed 26 July 2017).

42. Califf RM, Robb MA, Bindman AB, et al. Transforming evidence generation to support health and health care decisions. N Eng/ J Med. 2016:375:2395-400.

43. Suissa S. Lower risk of death with SGLT2 inhibitors in observational studies: real or bias? Diabetes Care. 2018;41:6-10.

44. Cowley A. What is real-world data? 2016. Available at: http:// crcaustralia.com/media-releases/real-world-data/ (accessed 21 January 2017)

45. Cziraky M, Pollock, M. Real-world evidence studies. 2015. Available at: http://www.appliedclinicaltrialsonline.com/realworld-evidence-studies (accessed 4th April 2017).

46. Kosiborod M, Cavender MA, Fu AZ, et al. Lower risk of heart failure and death in patients initiated on sodium-glucose cotransporter-2 inhibitors versus other glucose-lowering drugs: the CVD-REAL study (comparative effectiveness of cardiovascular outcomes in new users of sodium glucose cardiovascular ou

77. Birkeland KI, Jorgensen ME, Carstensen B, et al. Cardiovascular mortality and morbidity in patients with type 2 diabetes mortality and morbidity in patients with type 2 diabetes
following initiation of sodium-glucose co-transporter-2 following initlation of sodium-glucose co-transporter-2
inhibitors versus other glucose-lowering drugs (CVD-REAL Nordic): a multinational observational analysis. Lancet Diabetes Nordic): a multinational obser.
Endocrinol. 2017;5:709-17.

48. Persson F, Nyström T, Jergensen ME, et al. Dapagliflozin is associated with lower risk of cardiovascular events and all-cause mortality in people with type 2 diabetes (CVD-REAL Nordic) when compared with dipeptidyl peptidase-4 inhibitor therapy: A multinational observational study. Diabetes Obes Metab. 2018;20:344-51.

49. Toulis $\mathrm{KA}$, Willis BH, Marshall $\mathrm{T}$, et al. All-cause mortality in patients with diabetes under treatment with dapagliflozin: a population-based, open-cohort study in The Health Improvement Network database. J Clin Endocrinol Metab. 2017:102:1719-25.

50. Nyström T, Bodegard J, Nathanson D, et al. Novel oral glucoselowering drugs are associated with lower risk of all-cause mortality, cardiovascular events and severe hypoglycaemi compared with insulin in patients with type 2 diabetes. Diabetes Obes Metab. 2017;19:831-41.

51. Yuan Z, DeFalco FJ, Ryan PB, et al. Risk of lower extremity amputations in people with type 2 diabetes mellitus treated with sodium-glucose co-transporter-2 inhibitors in the USA: A retrospective cohort study. Diabetes Obes Metab. 2018;20:582-9.

52. Piepoli MF, Hoes AW, Agewall S, et al. 2016 European Guidelines on cardiovascular disease prevention in clinical practice: The Sixth Joint Task Force of the European Society praction of Cardiology and Other Societies on Cardiovascular Disease Prevention in Clinical Practice (constituted by representat
of 10 societies and by invited experts) developed with the special contribution of the European Association for the special contribution of the European Association for Cardiovascular Preven

53. Ponikowski P, Voors AA, Anker SD, et al. 2016 ESC Guidelines for the diagnosis and treatment of acute and chronic heart failure: The Task Force for the diagnosis and treatment of acute and chronic heart failure of the European Society of Cardiology (ESC)Developed with the special contribution of the Heart Failure Association (HFA) of the ESC. Eur Heart J. 2016;37:2129-200

54. ADA. American Diabetes Accociation Standards of medical care in diabetes - 2017. Diabetes Care. 2017;40:S1-S2.

55. Kosiborod M, Cavender MA, Fu AZ, et al. Lower risk of heart failure and death in patients initiated on SGLT-2 inhibitors versus other glucose-lowering drugs: the CVD-REAL study. versus other glucose-lowering dr
Circulation. 2017:136:249-59.

56. Marso SP, Daniels GH, Brown-Frandsen K, et al. Liraglutide and cardiovascular outcomes in type 2 diabetes. N Eng/ J Med. 2016;375:311-22

57. Marso SP, Bain SC, Consoli A, et al. Semaglutide and cardiovascular outcomes in patients with type 2 diabetes. $N$ Engl J Med. 2016;375:1834-44

58. ClinicalTrials.gov. Multicenter trial to evaluate the effect of dapagliflozin on the incidence of cardiovascular events (DECLARE-TIMI58). 2017. Available at: https://clinicaltrials.gov/ ct2/show/NCT01730534 (accessed 5 April 2017). 